\title{
Retrospective analysis of the clinical efficacy of concurrent weekly cisplatinum - radiotherapy for patients with laryngeal carcinoma
}

\author{
Mohamed Abdelhamed Aboziada*1, Ashraf Elyamany ${ }^{2}$ \\ ${ }^{1}$ Department of Radiation Oncology, South Egypt Cancer Institute, Assiut University, Egypt \\ ${ }^{2}$ Department of Medical Oncology, South Egypt Cancer Institute, Assiut University, Egypt
}

\author{
Received: June 29, 2016 \\ Accepted: August 28, 2016 \\ Online Published: Sepember 7, 2016 \\ DOI: $10.5430 / \mathrm{jst.v7n} 1 \mathrm{p} 1$ \\ URL: http://dx.doi.org/10.5430/jst.v7n1p1
}

\begin{abstract}
Introduction and aim: Laryngeal preservation with concurrent chemo-radiation is an effective, alternative management for cancer larynx. Three weekly cis-platinum concurrent with radiotherapy (RT) considered the standard. However, weekly cisplatinum has proven very effective for advanced head and neck carcinoma. We review our data to prove the efficacy and safety of weekly cis-platinum plus RT for laryngeal preservation.

Patients and methods: Untreated 64 patients with advanced laryngeal carcinoma were retrospectively analyzed. Patients offered for 6 weeks of cis-platinum $40 \mathrm{mg} / \mathrm{m}^{2}$ concurrent with conformal RT; 70 Gy delivered to gross primary and lymph nodes.

Results: Forty-six (71.8\%) patients had complete remission (CR). Early stages had better CR than late stages. Median follow up was 40 months. Three years DFS and OS were 69\% and 77\% respectively. Larynx preservation survival at 3 years was $73 \%$. Protocol of treatment was tolerable, grade 3 or 4 acute and late toxic effects were reported in $25 \%$ of the included cases.

Conclusion: Weekly cis-platinum could be effective and safe. We need to evaluate this protocol prospectively and compare it with three-weekly high dose cis-platinum with concomitant radiotherapy.
\end{abstract}

Key Words: Larynx-cis-platinum, Preservation

\section{INTRODUCTION}

Total laryngectomy was the standard treatment for patients with locally advanced laryngeal carcinoma. This practice was changed to non-surgical approach; chemo-radiation (CRT) is currently considered as a standard of care. After more than 10 years follow-up, no significant survival difference was reported between laryngectomy and chemo-radiation. ${ }^{[1]}$ The ability of larynx preservation without negative survival impact established CRT as an alternative treatment to laryngectomy locally advanced laryngeal carcinoma. ${ }^{[2,3]}$ Concomitant chemo-radiation was reported to be better than induction chemotherapy followed by radiation therapy (RT) as regard the rate of laryngeal preservation, and loco-regional control. $^{[4]}$

Cis-platinum is the standard chemotherapy, however, The optimal cis-platinum administration approaches still controversial. ${ }^{[5]}$ Many centers refer to $100 \mathrm{mg} / \mathrm{m}^{2}$ dose given on (days 1, 22, and 43) with RT as the standard. However, this schedule was initially developed to be used as induction chemotherapy then it was incorporated into CRT regimens. There is no randomized trials compare this schedule with

\footnotetext{
*Correspondence: Mohamed Abdelhamed Aboziada; Email: maboziada70@yahoo.com; Address: Department of Radiation Oncology, University of Assiut, South Egypt Cancer Institute, El-Methak St., Assiut, Egypt.
} 
others. Weekly cis-platinum was found to be a more feasible option with acceptable toxicity and lesser treatment interruptions $(<15 \%){ }^{[5,6]}$ This regimen showed similar control rates when compared to routinely practiced 3 weekly high dose CRT. ${ }^{[6]}$ The feasibility of weekly cis-platinum is based on the evidence that a cumulative therapeutic chemotherapy dose $\left(>200 \mathrm{mg} / \mathrm{m}^{2}\right)$ considered to be essential for therapeutic benefit. ${ }^{[7]}$

\section{Aim of study}

To evaluate: 1) The larynx preservation, rates of disease control and overall survival. 2) Safety with weekly cis-platinum in our patients as regard of acute and late toxicity.

\section{Patients And Methods}

We analyzed 102 consecutive patients with non-metastatic laryngeal carcinoma who were referred to our Cancer institute between 2007 and 2011. Sixty-four patients were eligible and treated with combined chemo-radiation. Eligibility criteria were as follows: previously untreated, histologically proven squamous cell carcinoma (SCC) stage III, IV without distant metastasis. Eastern Cooperative Oncology Group performance status of 0-2. Patients previously received RT to the head and neck region were excluded. Patients staging was done according to the standard International Union Against Cancer (UICC) 6th edition. Pretreatment evaluations were as follows: a physical examination, normal (blood cells count, liver, and renal profiles), laryngeal endoscopy, the neck and chest computed tomography (CT), and abdominal sonography.

\subsection{Combined chemo-radiation}

Patients were treated with concurrent weekly cis-platinumradiation. Those patients offered weekly cis-platinum $40 \mathrm{mg} / \mathrm{m}^{2}$ after good hydration and anti-emetic medications. Chemotherapy was given for 6 weeks. Dose of radiation was 66-70 Gy/33-35 fractions/7 weeks, 2 Gy per fraction for gross target volume primary and involved nodes (GTV), 60 Gy/30 fractions/6 weeks for high-risk clinical target volume (CTV) including whole larynx, stoma, level II, II, IV nodes in the involved node neck, and $50 \mathrm{~Gy} / 25$ fractions/5 weeks for low risk CTV including posterior neck and supra-clavicular area.

CT-simulation was done for patients with thermoplastic sheet fixation for head, shoulders and extended head. Delineation of target volumes and organs at risk were done. Conformal radiotherapy was delivered with respect to tolerance of organs at risk. Conformal radiotherapy was delivered 40-44 Gy to the whole neck then spares the spinal cord, with an additional boost of 22-26 Gy being delivered to the gross tumor and involved lymph node using the cone down technique; lateral tangential fields and/ or electron beam. Planned neck dissection was considered for patients with initially bulky nodes $>3 \mathrm{~cm}$ or suspicious residual nodal disease 8 weeks after the completion of CRT. Salvage surgery was indicated in cases with documented residual or progression of either the primary or neck lesion.

\section{Follow-up}

Eight weeks after the completion of CRT, initial treatment responses were assessed using laryngeal endoscopy, and CT neck. A biopsy was taken for histopathology if there was a residual tumor. We followed patients every month for the first 6 months and bimonthly to 1 year after the completion of CRT, every 3 and 4 months for 2 nd and 3rd years respectively and then yearly thereafter. In each follow-up, physical examination and laryngoscopy were performed, in addition to head and neck and chest CT scanning every six months during first 2 years, then annually during the follow-up.

Acute toxicity was scored according to CTCAE (Common Terminology Criteria of Adverse Events version 3.0). ${ }^{[8]}$ Late toxicity was scored according to RTOG(Radiation Therapy Oncology Group morbidity grading scale). ${ }^{[9]}$

\subsection{Statistical analysis}

Overall survival (OS) was defined as the time from the start of treatment to death from any cause. Progression-free survival (PFS) was calculated from the start of treatment to death by any cause, local/regional progression or distant metastasis. Larynx preservation survival (LPS) was defined as the time from the start of treatment to death from any cause, salvage laryngectomy. OS, PFS and LPS rates were estimated using the Kaplan-Meier method. ${ }^{[10]}$ Log-rank test was performed for comparisons of survival differences, and chi-square test was used for comparing percentages. The $P$-values were double-sided $(P \leq .05$ were considered statistically significant).

\section{RESULTS}

Sixty-four patients assigned for chemo-radiation for laryngeal preservation. Forty-two patients were male and 22 patients were female. Thirty-five patients had positive active smoking and 15 patients had passive smoking. Age of patients ranged from 34 to 75 years. The median age was 56 years. The majority of our patients were men and smokers. Hoarseness of voice was the commonest complaints followed by cervical lymphadenopathy and difficult swallowing. The gap between initial complaint and diagnosis was 6-12 months. About $87 \%$ of our patients presented with nodal involvement (see Table 1). 
Table 1. Patients' characteristics

\begin{tabular}{llll}
\hline & & Number (64) & \% \\
\hline \multirow{2}{*}{ Sex } & Male & 42 & 65.6 \\
& Female & 22 & 34.4 \\
& Supraglottis & 43 & 67.1 \\
& Glottis & 21 & 32.9 \\
& Tx & 7 & 10.9 \\
Tumor & T1 & 7 & 10.9 \\
stage & T2 & 26 & 40.5 \\
& T3 & 19 & 29.7 \\
& T4 & 5 & 8 \\
Nodal & N0 & 8 & 12.5 \\
stage & N1 & 19 & 29.7 \\
& N2 & 30 & 46.9 \\
& N3 & 7 & 10.9 \\
Grade & Well & 3 & 4.8 \\
& Moderate & 33 & 51.5 \\
& Poor & 28 & 43.7 \\
\hline
\end{tabular}

Table 2. Factors affecting the response to chemo-radiation

\begin{tabular}{lllll}
\hline & CR (46) & No CR (18) & Total (64) & P value \\
\hline Grade & & & & \\
Well & 2 & 1 & 3 & .9 \\
Moderate & 24 & 9 & 33 & \\
poor & 20 & 8 & 28 & \\
Tumor & & & & \\
Tx & 4 & 3 & 7 & .005 \\
T1 & 7 & 0 & 7 & \\
T2 & 20 & 6 & 26 & \\
T3 & 15 & 4 & 19 & .0003 \\
T4 & 0 & 5 & 5 & \\
Node & & & & \\
N1 & 18 & 1 & 19 & .5 \\
N2 & 20 & 10 & 30 & \\
N3 & 0 & 7 & 7 & \\
Site & & & 43 & \\
Supra-glottis & 32 & 11 & 21 & \\
Glottis & 14 & 7 &
\end{tabular}

Note. CR: complete remission. No (8 patients).

Table 3. Survival analysis

\begin{tabular}{|c|c|c|c|c|c|c|c|c|}
\hline \multirow{2}{*}{\multicolumn{2}{|c|}{ Prognostic factor }} & \multirow{2}{*}{$N(64)$} & \multicolumn{6}{|c|}{ 3-year survival rate (\%) } \\
\hline & & & OS & $P$ & PFS & $P$ & LPS & $\boldsymbol{P}$ \\
\hline \multirow{2}{*}{ Sex } & Male & 42 & 76 & \multirow{2}{*}{.83} & 66 & \multirow{2}{*}{.64} & 71 & \multirow{2}{*}{.75} \\
\hline & Female & 22 & 78 & & 71 & & 75 & \\
\hline \multirow{2}{*}{ Site } & Glottis & 21 & 79.2 & \multirow{2}{*}{.65} & 72 & \multirow{2}{*}{.82} & 75 & \multirow{2}{*}{.42} \\
\hline & Supraglottis & 43 & 76.5 & & 66 & & 64 & \\
\hline \multirow{2}{*}{ T stage } & T1-T2 & 33 & 88 & \multirow{2}{*}{.001} & 77 & \multirow{2}{*}{.001} & 81 & \multirow{2}{*}{.001} \\
\hline & T3-T4-Tx & 31 & 63.5 & & 50 & & 55 & \\
\hline \multirow{2}{*}{$\mathrm{N}$ stage } & N0-N1 & 27 & 87 & \multirow{2}{*}{.001} & 78.4 & \multirow{2}{*}{.001} & 80 & \multirow{2}{*}{.002} \\
\hline & N2-N3 & 37 & 62 & & 48.5 & & 52.4 & \\
\hline \multirow{2}{*}{ Grade } & Moderate & 33 & 82 & \multirow{2}{*}{.5} & 78 & \multirow{2}{*}{.4} & 79 & \multirow{2}{*}{.43} \\
\hline & Poor & 28 & 75 & & 63 & & 65 & \\
\hline
\end{tabular}

Forty six (71.8\%) patients had a complete remission (CR) of the primary tumor. Among 56 patients presented with cervical lymphadenopathy, 38 patients had CR. Tumor/nodal factors are the only significant factors affecting the response to chemo-radiation (see Table 2). Patients who didn't achieve CR offered salvage surgery. Patients were stratified according to primary tumor site (glottis or supraglottis), grade, and T-N stage. Patients assessed for DFS, OS and LPS. Median follow-up period was 40 months. Three years DFS and OS were $69 \%$ and $77 \%$ respectively (see Figures 1-2). Larynx preservation survival at 3 years was $73 \%$. Tumor/Nodal status were the only significant factors affecting OS, DFS, and LPS (see Table 3). Patients who presented with early stages; T1-2, N0-N1 had significantly better OS, DFS, and LPS than those presented with advanced tumor.

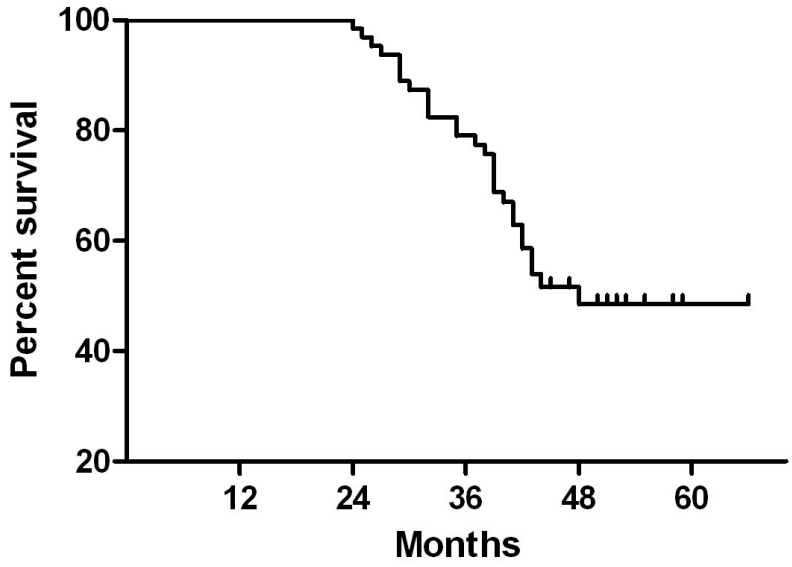

Figure 1. Overall survival proportions 


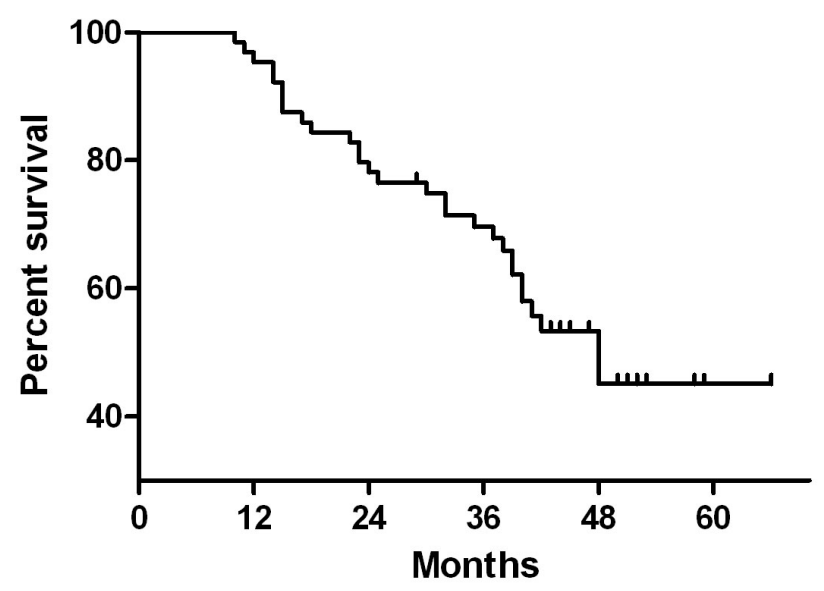

Table 4. Acute and late toxicity

\begin{tabular}{lll}
\hline & G3 & G4 \\
\hline Acute toxicity & & \\
Haematology & 2 & 1 \\
Stomatitis & 4 & 0 \\
Dysphagia & 1 & 0 \\
Laryngeal edema & 2 & 0 \\
Dermatitis & 2 & 0 \\
Vomiting & 2 & 0 \\
Late toxicity & & \\
Laryngeal & 2 & 0 \\
Stenosis & & 0 \\
\hline
\end{tabular}

Figure 2. Disease free survival proportions

Table 5. Randomized trials of larynx preservation for laryngeal SCC

\begin{tabular}{|c|c|c|c|c|c|}
\hline Study ${ }^{\text {[ref] }}$ & Patients criteria & Patients number & Protocol & OS & $\mathbf{L P}$ \\
\hline \multirow{2}{*}{$\mathrm{VA}^{[1,20]}$} & \multirow{2}{*}{$\begin{array}{l}\text { Stage III/IV } \\
\text { laryngeal SCC } \\
\text { No T1N1 }\end{array}$} & \multirow[b]{2}{*}{332} & Surgery + RT & $\begin{array}{l}68 \% \\
(2 \text { years) }\end{array}$ & - \\
\hline & & & $\begin{array}{l}\mathrm{PF}+(\mathrm{RT} \text { if } \\
\text { Regression } \geqslant 50 \%)\end{array}$ & $68 \%$ & $66 \%$ \\
\hline \multirow{2}{*}{ GETTEC $^{[21]}$} & \multirow{2}{*}{$\begin{array}{l}\text { Laryngeal SCC T3, } \\
\text { N0-N2b }\end{array}$} & \multirow{2}{*}{68} & Surgery + RT & $\begin{array}{l}84 \% \\
(2 \text { years) }\end{array}$ & - \\
\hline & & & $\begin{array}{l}\mathrm{PF}+(\mathrm{RT} \text { if } \geqslant 80 \% \\
\text { Regression) }\end{array}$ & $\begin{array}{l}69 \% \\
(2 \text { years) }\end{array}$ & $\begin{array}{l}42 \% \\
\text { ( } 2 \text { years) }\end{array}$ \\
\hline \multirow{3}{*}{ RTOG $91-11^{[4]}$} & \multirow{3}{*}{$\begin{array}{l}\text { All the patients had vocal } \\
\text { cord fixation Stage III/IV } \\
\text { laryngeal SCC } \\
\text { No T1 or large volume T4 }\end{array}$} & \multirow{3}{*}{547} & $\mathrm{PF}+(\mathrm{RT}$ if $\mathrm{CR}$ or $\mathrm{PR})$ & $\begin{array}{l}38.5 \% \\
\text { (10 years) }\end{array}$ & $\begin{array}{l}67.5 \% \\
\text { (10 years) }\end{array}$ \\
\hline & & & CCRT & $\begin{array}{l}27.5 \% \\
\text { (10 years) }\end{array}$ & $\begin{array}{l}81.7 \% \\
\text { (10 years) }\end{array}$ \\
\hline & & & RT alone & $\begin{array}{l}31.5 \% \\
\text { (10 years) }\end{array}$ & $\begin{array}{l}63.8 \% \\
\text { (10 years) }\end{array}$ \\
\hline \multirow{2}{*}{ EORTC $24954^{[22]}$} & \multirow{2}{*}{$\begin{array}{l}\text { T3-T4, N0-N2 } \\
\text { laryngeal SCC }\end{array}$} & \multirow{2}{*}{224} & Sequential $\mathrm{PF} \geqslant \mathrm{RT}$ & $\begin{array}{l}64.8 \% \\
\text { (3 years) }\end{array}$ & $\begin{array}{l}45.4 \% \\
\text { ( } 3 \text { years) }\end{array}$ \\
\hline & & & Alternating PF/RT & $\begin{array}{l}51.9 \% \\
(5 \text { years) }\end{array}$ & $\begin{array}{l}36.2 \% \\
\text { (5 years) }\end{array}$ \\
\hline
\end{tabular}

Note. SCC: squamous cell carcinoma, PR: partial response, CR: complete response, RT: radiotherapy, CCRT: concomitant chemor-adiotherapy, PF: Cisplatin and 5-Fluorouracil.

Low dose weekly cis-platinum concurrent CRT was tolerable with low incidence of G3 and G4 acute toxicity. Severe acute toxicities are listed in Table 4. Acute G3 and G4 toxicities were experienced in 14 (21\%) patients. Hematological toxicity and stomatitis were the commonest toxicity. Grade 3 or 4 neutropenia was the most common hematological toxicity (3 patients). All the included patients were able to complete the planned 6 cycles of chemotherapy. Interruption of treatment was very low $(<5 \%)$. Modification of dose of chemotherapy was individual and reported in $<10 \%$. No treatment-related mortalities were reported. As regard to late effects, 2 patients had G3 laryngeal stenosis. Most of the late effects were grade 2 and referable to the larynx, pharynx, salivary glands, thyroid, and subcutaneous tissues. Acute and chronic xerostomia were problems in almost all patients.

\section{Discussion}

Cisplatin (100 mg/m $\mathrm{m}^{2}$ given on days 1,22 , and 43$)$ concurrent with RT is the standard regimen for laryngeal preservation and also for advanced HNC patients. ${ }^{[2-4]}$ This regimen is associated with significant acute and late toxicities and most of the patients don't complete 3 cycles..$^{[2,11,12]}$ Nearly one-third of patients do not receive all cycles, and subset analyses suggest that two cycles are as effective as three. 
Weekly cisplatin $\left(40 \mathrm{mg} / \mathrm{m}^{2}\right)$ is a well-tolerated regimen, even with the large RT fields employed for nasopharyngeal carcinoma treatment. ${ }^{[13,14]}$ Weekly schedule has more regularly monitored for toxicity, easier to manage than three weekly cisplatin. Furthermore, the weekly schedule can be modified based on the patient's tolerance to avoid severe toxicities. More frequent chemotherapy administration could provide radiosensitizing effect to a larger administered RT dose proportion. ${ }^{[5-7]}$ Concurrent CRT with weekly cisplatin has proven to be very effective and has been considered as the standard of care in the treatment of squamous carcinoma of the cervix. ${ }^{[15,16]}$ Also, weekly cisplatin has been used successfully in concurrent CRT for bladder preservation. ${ }^{[17,18]}$

In a study from New Cross Hospital, UK; ${ }^{[19]}$ they retrospectively compared the differences in dose intensity, treatment delay and treatment-related toxicity between the weekly and three weekly cisplatin protocols when concurrently administered with RT to treat patients with locally advanced HNC. Cisplatin $\left(100 \mathrm{mg} / \mathrm{m}^{2}\right) 3$-weekly with concurrent RT was found to be less tolerated than $40 \mathrm{mg} / \mathrm{m}^{2}$ weekly regimen, with fewer patients achieved cumulative dose beyond $200 \mathrm{mg} / \mathrm{m}^{2}$, which decrease chemotherapy dose intensity. Weekly cisplatin has been the standard concomitant schedule with RT for treatment of locally advanced HNC, squamous cell carcinoma, in some centers. ${ }^{[7,19]}$

We reported the efficacy of weekly cis-platinum concurrent with RT; 3 years DFS, OS and LPS were 69\%, 77\% and $73 \%$ respectively. Our clinical results were consistent with other series; in spite of the smaller sample size with a shorter follow-up period. The clinical results of organ preservation using CRT were shown in Table 5. Some of these trials used a high dose of 3 weekly cis-platinum concurrents with RT.

We reported a high incidence of xerostomia due to large volume of parotids irradiated. Intensity modulated radiation treatments (IMRT) delivers a highly conformal radiation dose to target volumes, sparing the surrounding normal tissues. IMRT has been clinically used and significantly decreases the incidence of xerostomia due to parotid sparing and improves the quality of life. ${ }^{[23,24]}$ The advantage of parotid sparing by IMRT has been reported in cases of NPC or OPC. The same benefit was also observed in series for laryngeal preservation patients. IMRT increased the rate of laryngeal preservation and decreases the incidence of late toxicity. ${ }^{[25-27]}$

\section{Conclusions}

To our knowledge, this is the first study that used weekly cisplatin concurrent with RT in laryngeal preservation. Our trial had many limitations. Since it was a single institution, retrospective study, and small sample size with a short followup period, there were several biases. However, our results were consistent with previous series used three weekly cisplatin. We need to evaluate this protocol prospectively and compare it with three-weekly high dose cis-platinum with concomitant radiotherapy.

\section{CONFLICTS OF INTEREST Disclosure}

The authors declare that there is no conflict of interest statement.

\section{REFERENCES}

[1] The Department of Veterans Affairs Laryngeal Cancer Study Group. Induction chemotherapy plus radiation compared with surgery plus radiation in patients with advanced laryngeal cancer. N Engl J Med. 1991; 324(24): 1685-90. PMid:2034244. http://dx.doi.org/10. 1056/NEJM199106133242402

[2] Forastiere AA, Goepfert H, Maor M, et al. Concurrent chemotherapy and radiotherapy for organ preservation in advanced laryngeal cancer. N Engl J Med. 2003; 349(22): 2091-8. PMid:14645636. http://dx.doi.org/10.1056/NEJMoa031317

[3] Lefebvre JL. Candidates for larynx preservation: the next step? Oncologist. 2010; 15(Suppl 3): 30-2. PMid:21036887. http://dx.d oi .org/10.1634/theoncologist.2010-S3-30

[4] Forastiere AA, Zhang Q, Weber RS, et al. Long-term results of RTOG 91-11: A comparison of three nonsurgical treatment strategies to preserve the larynx in patients with locally advanced larynx cancer. J Clin Oncol. 2013; 31(7): 845-52. PMid:23182993. http://dx.doi.org/10.1200/JC0.2012.43.6097

[5] Brizel DM, Esclamado R. Concurrent Chemoradiotherapy for Locally Advanced, Nonmetastatic, Squamous Carcinoma of the Head and Neck: Consensus, Controversy, and Conundrum. J Clin Oncol.
2006; 24: 2612-7. PMid:16763273. http://dx.doi.org/10.12 $00 / \mathrm{JC0} .2005 .05 .2829$

[6] Gupta T, Agarwal JP, Ghosh-Laskar S, et al. Radical radiotherapy with concurrent weekly cisplatin in loco-regionally advanced squamous cell carcinoma of the head and neck: A single-institution experience. Head Neck Oncol. 2009; 1: 17. PMid:19527507. http: //dx.doi.org/10.1186/1758-3284-1-17

[7] Homma A, Inamura N, Oridate N, et al. Concomitant Weekly Cisplatin and Radiotherapy for Head and Neck Cancer. Jpn J Clin Oncol. 2011; 41(8): 980-6. PMid:21715362. http://dx.doi .org/10.10 93/jjco/hyr086

[8] Common Toxicity Criteria Version 3. Available from: http://ctep.cancer.gov/protocolDevelopment/elec tronic_applications/docs/ctcaev3.pdf.

[9] Cox JD, Stetz J, Pajak TF. Toxicity criteria of the Radiation Therapy Oncology Group (RTOG) and the European Organization for Research and Treatment of Cancer (EORTC). Int J Radiat Oncol Biol Phys. 1995; 31: 1341-6. http://dx.doi.org/10.1016/0360-3 016(95) 00060-C

[10] Kaplan EL, Meier P. Nonparametric estimation from incomplete ob- 
servations. J Am Stat Assoc. 1958; 53: 457-81. http://dx.doi.o rg/10.1080/01621459.1958.10501452

[11] Machtay M, Moughan J, Trotti A, et al. Factors associated with severe late toxicity after concurrent chemoradiation for locally advanced head and neck cancer: an RTOG analysis. J Clin Oncol. 2008; 26: 3582-9. PMid:18559875. http://dx.doi.org/10.1200/JC0.2 007.14 .8841

[12] De Castro G, Jr, Snitcovsky IM, Gebrim EM, et al. High-dose cisplatin concurrent to conventionally delivered radiotherapy is associated with unacceptable toxicity in unresectable, non-metastatic stage IV head and neck squamous cell carcinoma. Eur Arch Otorhinolaryngol. 2007; 264: 1475-82. PMid:17643256. http://dx.doi.org/1 $0.1007 / \mathrm{s} 00405-007-0395-9$

[13] Isobe K, Kawakami H, Uno T, et al. Concurrent chemoradiotherapy for locoregionally advanced nasopharyngeal carcinoma: is intergroup study 0099 feasible in Japanese patients? Jpn J Clin Oncol. 2003; 33: 497-500. PMid:14623916. http://dx.doi.org/10.1093/jjco/ hyg094

[14] Chan AT, Leung SF, Ngan RK, et al. Overall survival after concurrent cisplatin-radiotherapy compared with radiotherapy alone in locoregionally advanced nasopharyngeal carcinoma. J Natl Cancer Inst. 2005; 97: 536-9. PMid:15812080. http://dx.doi.org/10.1093 /jnci/dji084

[15] Peters WA III, Liu PY, Barrett RJ II, et al. Concurrent chemotherapy and pelvic radiation therapy compared with pelvic radiation therapy alone as adjuvant therapy after radical surgery in high-risk early-stage cancer of the cervix. J Clin Oncol. 2000; 18: 1606-13. http://dx.doi.org/10.1097/00006254-200008000-00017

[16] Thomas GM. Improved treatment for cervical cancer-concurrent chemotherapy and radiotherapy. N Engl J Med. 1999; 340: 1198200. PMid:10202172. http://dx.doi.org/10.1056/NEJM199 904153401509

[17] Aboziada MA, Hesham MH, Ahmed MA. Initial Results of bladder preserving approach by chemo-radiatiotherapy in patients with muscle invading transitional cell carcinoma. Journal of the Egyptian Nat. Cancer Inst. 2009; 21(2): 167-74.

[18] Mak RH, Hunt D, Shipley WU, et al. Long-Term Outcomes in Patients With Muscle-Invasive Bladder Cancer After Selective BladderPreserving Combined-Modality Therapy: A Pooled Analysis of RTOG Protocols 8802, 8903, 9506, 9706, 9906, and 0233. J Clin Oncol. 2014; 32: 3801-9. PMid:25366678. http://dx.doi.org/1 $0.1200 / \mathrm{JCO} .2014 .57 .5548$
[19] Ho KF, Swindell R, Brammer CV. Dose intensity comparison between weekly and 3-weekly Cisplatin delivered concurrently with radical radiotherapy for head and neck cancer: A retrospective comparison from New Cross Hospital, Wolverhampton, UK. Acta Oncol 2008; 47: 1513-8. PMid:18607863. http://dx.doi.org/10.10 80/02841860701846160

[20] Spaulding MB, Fischer SG, Wolf GT, et al. Tumor response, toxicity, and survival after neoadjuvant organ preserving chemotherapy for advanced laryngeal carcinoma. Journal of Clinical Oncology. 1994; 12: 1592-9. PMid:8040671.

[21] Richard JM, Sancho-Garnier H, Pessey JJ, et al. Randomized trial of induction chemotherapy in larynx carcinoma. Oral Oncology. 1998; 34: 224-8. http://dx.doi.org/10.1016/S1368-8375(97)0 0090-0

[22] Lefebvre JL, Rolland F, Tesselaar M, et al. Phase 3 randomized trial on larynx preservation comparing sequential vs alternating chemotherapy and radiotherapy. Journal of the National Cancer Institute. 2009; 101: 142-52. PMid:19176454. http://dx.doi.org/1 $0.1093 / j n c i / d j n 460$

[23] Kam MKM, Leung SF, Zee B, et al. Prospective randomized study of intensity-modulated radiotherapy on salivary gland function in earlystage nasopharyngeal carcinoma patients. Journal of Clinical Oncology. 2007; 25: 4873-9. PMid:17971582. http://dx.doi.o rg/10.1200/JC0.2007.11.5501

[24] Nutting CM, Morden JP, Harrington KJ, et al. Parotid-sparing intensity modulated vs conventional radiotherapy in head and neck cancer (PARSPORT): A phase 3 multicentre randomized controlled trial. Lancet Oncology. 2011; 12(2): 127-36. http://dx.doi .org/10. 1016/S1470-2045(10)70290-4

[25] Guerrero Urbano T, Clark CH, Hansen VN, et al. A phase I study of dose-escalated chemo-radiation with accelerated intensity modulated radiotherapy in locally advanced head and neck cancer. Radiotherapy and Oncology. 2007; 85(October 1): 36-41.

[26] Miah AB, Bhide SA, Guerrero-Urbano MT, et al. Dose-escalated intensity-modulated radiotherapy is feasible and may improve locoregional control and laryngeal preservation in laryngo-hypopharyngeal cancers. International Journal of Radiation Oncology, Biology, Physics. 2012; 82(2): 539-47. PMid:21236602. http://dx.doi .org/10.1016/j.ijrobp.2010.09.055

[27] Lee NY, O'Meara W, Chan K, et al. Concurrent chemotherapy and intensity-modulated radiotherapy for locoregionally advanced laryngeal and hypopharyngeal cancers. International Journal of Radiation Oncology, Biology, Physics. 2007; 69(2): 459-68. PMid:17493769. http://dx.doi.org/10.1016/j.ijrobp.2007.03.013 